\title{
Universal Design for Learning in the University Classroom
}

\author{
Patricia Kohler-Evans ${ }^{1}$, Chayla D. Rutledge ${ }^{1} \&$ Candice Dowd Barnes $^{1}$ \\ ${ }^{1}$ University of Central Arkansas, Conway, Arkansas, USA \\ Correspondence: Patricia Kohler-Evans, University of Central Arkansas, Conway, Arkansas, USA. Tel: \\ 501-450-3171.
}

Received: February 4, 2019

Accepted: March 12, 2019

Online Published: March 13, 2019

doi:10.5430/irhe.v4n1p38

URL: https://doi.org/10.5430/irhe.v4n1p38

\begin{abstract}
Universal Design for Learning (UDL) is based on the architecture and industrial design paradigm, universal design. The UDL framework provides guidelines for teachers when they create, instruct, and assess the delivery of content. Based on three underlying principles: multiple means of representation, action and expression, and engagement, UDL targets the needs of every learner in the classroom. Although much has been written about UDL in the K-12 classroom, the principles apply equally to higher education. Most faculty are well versed in the delivery of content through a traditional lecture format, yet few consider applying UDL principles. It is not enough that an instructor provide knowledge. He or she must also ensure that critical content is accessible to all students entering the university classroom. Faculty members recognized for their excellence in teaching include teaching strategies that are aligned to UDL principles. These strategies include creation of positive learning environments, use of humor, active engagement vs passive engagement, and explicit structure. The primary purpose of the article is threefold: to discuss the importance of using a UDL approach in higher education, to help faculty begin using a UDL approach through professional development, and sharing strategies for students in the higher education classroom. Recommendations are made for providing professional development to faculty to increase their use of universal design for learning principles with questions for consideration. Additional recommendations are made for teaching students through the UDL lens. By using a UDL framework, all students have access to curriculum in ways meaningful to each individual.
\end{abstract}

Keywords: universal design for learning, strategies, inclusion, professional development

\section{Introduction}

Universal Design for Learning (UDL) comes from the universal design paradigm that is well known in architecture and industrial design. The expression was coined by Ronald Mace and operates under the principles of creating designs that can be used by all people to the greatest extent possible. The foundational belief that undergirds UDL suggests that if we create programs and services to be accessible from the beginning, then we do not have to spend time or money making accommodations and modifications later on.

UDL is a framework that places focus on the variability in learning. This framework provides guidelines for teachers to use when they create, teach and assess their content. It is theoretical and based in neuroscience research. The brain has three networks that contribute to learning. The first network is recognition, or the what of learning, and how we categorize what we are learning. The second network is the strategic network, or the how of learning, which is how we organize and express ideas. The final network is the affective network, or the why of learning, and how we connect what we learn to our own experiences and background (Rose \& Myer, 2002 as cited in Mangiatordi \& Serenelli, 2013).

Educators need to take into consideration that all students are different and learn in different ways and at different rates. Consequently, there are three principles of UDL which correspond with the brain networks: (1) provide multiple means of representation, (2) provide multiple means of action and expression, and (3) provide multiple means of engagement. Advancements in educational technology have made these principles far more attainable in recent years.

The purpose of this article is threefold. First, the importance of using a UDL approach will be discussed; second, recommendations for providing high quality professional development to faculty wishing to utilize UDL will be provided; and last, several strategies for infusing UDL into the university classroom will be made. This article highlights the need for more research to be conducted with the UDL framework; however, research that has been 
conducted points to increased attention to making learning accessible for all in teaching practices which result in improved academic gains.

\section{The Importance of the UDL Approach}

With increasing diversity in the public school system there has been increasing attention devoted to addressing the needs of all of the students in the classroom. The majority of the UDL literature comes from K-12 literature; however, this shows the benefits of using this strengths-based approach. Teachers in the 21 st century are facing a plethora of new challenges, including bringing special education into the general education classroom with the inclusion movement, technological advancements, increased classroom diversity, increased class sizes, etc.(Katz, 2015). UDL has beneficial outcomes for both students and teachers (Katz, 2015). One study measured teachers' perceptions as an outcome. It was found that teachers using UDL perceived improved student outcomes such as, reductions in challenging behavior, improved peer interactions, and higher levels of both learning and engagement. The teachers also reported that they experienced benefits, such as higher levels of self-efficacy, decreased workload, and improved job satisfaction (Katz, 2015).

UDL can transform the classroom, but flexibility is essential (Grogan \& Ruzic, 2000). According to Gogan \& Ruzic (2000), creating a UDL website, strategy, material, etc. requires a thoughtful process. First, you establish the goals of the material. Once the goals are established, barriers need to be identified and considered. The material needs to accommodate all types of users and individual differences need to be taken into consideration and addressed to the best of the designer's' ability. This can be done with the universal design for learning framework in mind, which includes the three systems of the brain mentioned above: recognition, strategic, and affective. Therefore, it is important to identify barriers to recognition of the content and concepts, barriers to interaction and navigation, and barriers to engagement with the site (Grogan \& Ruzic, 2000). No one material is going to work for all users and it is important to identify alternatives and allow for flexibility.

Increased diversity has trickled out of K-12 and into the university setting. The challenges universities are facing are the same as $\mathrm{K}-12$, meeting the needs of all the students in an ever-diversified world. UDL is one potential solution that needs to be explored. Some are beginning to explore this as an option; for example, Lohmann, Boothe, Hathcote, \& Turpin (2018) explored the possibility of implementing UDL strategies in an online teacher preparation program. It was noted that even if students did not use all of the provided strategies, the students knew they were available, and it helped them feel more connected to both the professor and other students in the course (Lohmann et al., 2018).

Much effort in higher education is focused on ensuring that content is provided, learned, and applied. For most university instructors, emphasis is heavily placed on making sure that candidates understand critical concepts and are able to utilize those same concepts within their chosen new fields of study. For example, the aspiring chemist must understand the basic tenets of chemistry, but he or she must also have the skill to take that content and use it effectively in the laboratory. Similarly, the same holds true with the future accountant. A deep understanding of the principles of mathematics and ledger-keeping is just the beginning. The accountant must also be able to advise clients in the real world of expenditures, taxation, and applicable law.

McGuire and Scott (2009) interviewed faculty members recognized as outstanding teachers, asking them about effective and recommended instructional strategies. The researchers also inquired about professional development opportunities that had been useful. The interviewed faculty members were designated as University Teaching Fellows, a high honor among faculty. The faculty members who were interviewed indicated that they had observed growing student diversity, and as a result, they were using a variety of approaches and strategies in their classrooms. From the study of outstanding teachers, several key strategies were identified. These teachers revealed that they used explicit structure, actively engaged students, highlighted and repeated important points, and created a positive learning environment. They connected with students through humor and taught productive learning strategies to their students. It is important to remember that these faculty members were identified for their excellence in teaching, and all of the strategies identified fit within a UDL framework, which focuses on making instruction accessible for all students.

What complicates the acquisition of knowledge and the ability to use it in meaningful ways is the degree to which candidates understand and are able to manipulate newly learned content through their respective avenues of understanding. It is not enough that the instructor provide knowledge. He or she must also ensure that critical content is accessible to all those who have gained admittance into the university classroom. Thus, Universal Design for Learning becomes the critical lens through which instruction is carried out.

For most faculty, andragogy, the study of adult learning, has not been a source of significant, if any, investigation. In fact, most faculty would probably admit to a more pedagogical orientation. Traditional pedagogy assumes that learners 
need only what they need to know, and they have a subject-centered orientation to learning. These learning experiences are organized according to subject-matter units and content (Knowles, 1989). Knowles' (1989), andragogic assumptions suggest that adults need to know why they are learning something before they learn it, they prefer to be self-directed, and they are problem-centered in their orientation.

Universal Design for Learning and an andragogic approach have several elements in common. First, UDL and andragogy both emphasize the importance of how information is presented: andragogy relies on the variety of learner experiences, and UDL acknowledges that there is no one way of presenting information or transferring knowledge that works for all students. Both UDL and andragogy acknowledge the importance of learner expression, including an understanding of variances in prior knowledge as a threshold for exploration of new learning. Lastly, both UDL and andragogy support multiple means of engagement, which rely on both extrinsic and intrinsic motivation. Not all students are engaged by the same rewards or conditions, nor do they develop intrinsic motivation along the same path. Understanding how adults learn and applying the principles of Universal Design adds a level of complexity to the university classroom.

\section{Professional Development Recommendations}

In an effort to bring UDL to the university classroom, the authors developed high quality professional development recommendations infusing the principles of UDL with knowledge of adult learning in order to influence higher education faculty. These ideas have been used successfully in professional development activities provided by the authors to other faculty members. In addition to ideas for sharing the components of UDL with other faculty, there are several simple ideas for faculty who are moving toward a more UDL focused framework to use in their own classrooms. Many faculty, while fully understanding their respective fields, do not necessarily have full comprehension of delivering content in a manner that infuses universal design principles. The recommendations in this section are made in order to bridge the gap between content knowledge and instruction that is accessible to and for all students. While the following is not a research study, there is a plethora of research backing the effectiveness of professional development as a valuable resource for implementation of a new strategy.

All three come from a strong educational background with a diligent pursuit of excellence in both content to be delivered and the actual delivery itself. In order to be effective in conveying knowledge, it is imperative that the instruction be focused on learner/participant needs and learning preferences. The professional development recommendations incorporate numerous best practices regarding instructional procedure. These practices include modeling, high engagement activities, attention to a variety of learning preferences, and a demonstrated appreciation for differences among learners. In the paragraphs that follow, some ideas for a professional development to engage faculty in practices that incorporate UDL in their own teaching are presented.

Practices are infused throughout the professional development recommendations. It is also recommended that any professional development activities include development of individual action plans by faculty for implementation, follow up coaching and fidelity of implementation checks. The purpose of fidelity of implementation checks is to provide peer to peer feedback from a colleague who has a deeper understanding of UDL and to ensure principles are being consistently incorporated appropriately.

At the conclusion of this article, readers will find a suggested action plan form that may be helpful. Many of the following recommendations for professional development can also be incorporated into a classroom setting. It is the believed that by providing high quality professional development to faculty, they will, in turn, provide high quality instruction to their students. It is recommended that professional development begin with defining the concept of Universal Design for Learning and giving participants an opportunity to identify what they currently know and what they are curious about. Use of a Know, What You Wish to Know and What You Learned (KWL) chart is recommended. Engaging in conversation early in the professional development ensures learners participate in the discussion and helps to demonstrate that their voice will be heard. Frequently, instructors deliver content without incorporating the experiences of learners and seeking to explore those experiences. Participant voice is critical and contributes to the practice of high engagement as well as modeling. By honoring voice in professional development with faculty, it is believed that faculty will in turn honor voice in their instructional settings. Thus a KWL chart can be used both in professional development, as well as in the actual classroom setting.

One of the goals of any educational process is teaching how to access knowledge, not just mastering knowledge. When curricula targets the broad middle (i.e. students performing in the middle, not the top or the bottom of the class) while excluding those with differing abilities, learning styles, backgrounds and preferences, they fail to provide all learners with fair and equal opportunities to learn. How knowledge is accessed frequently depends on opportunities for access. 
It stands to reason then, that professional development should incorporate knowledge of participants, their preferences for learning, and their experiences and backgrounds. The professional development should serve as a model.

Following a discussion of what participants want to know, an exploration of how participants learn can be facilitated in a variety of ways. Traditional learning style inventories have been used for decades although research suggests that there is little to no impact on achievement when learning styles are utilized. Some ideas for gathering information about participants includes, asking them to share information about personal interests and learning preferences through the use of a questionnaire. This may include inquiring about activities they are involved in outside of class and what learning preferences they may have (working in a group vs working with one other individual).

Other ways to identify learner interests and target the how might be asking them to construct a life journey/timeline, a dream or vision board, or even a collage representing themselves and how they see themselves as learners. A commercially available product that generates some of this information is the Learning Express-ways ${ }^{\mathrm{TM}}$ folder. Just like the KWL chart can be used for both professional development and in the classroom, so too can a learner preference process be used in both settings.

In order to develop a deeper understanding of the principles of UDL, the authors recommend spending time processing after each professional development activity. For example, after completing a questionnaire, survey or assessment regarding individual learning, it is appropriate to discuss how engaging in such activities helps one be a more effective instructor and how students might become more engaged in the content. For example, after participants individually think about ways they learn or prefer to engage, a table or small group discussion allows participants to discover commonalities with others who may teach similar or different content. Giving each small group specific tasks to complete in discussion can help the discussion be productive and efficient. For instance, the group facilitator may use a kitchen or smartphone timer to limit the discussion time and provide questions for processing. Some questions that might be asked include

- Why is learner preference important?

- How do you match your preferences for teaching to your students' preferences for learning?

- What did you learn about yourself in this activity?

Utilizing Universal Design in the university classroom does not have to be difficult. Another activity that might be used in professional development focused on using learner interests and preferences includes a deeper discussion of how participants design their lectures as well as the products they ask students to provide. By considering the Visual, Oral, and Written aspects of teaching, student engagement is likely to increase. Thus, any professional development activity serves well when it incorporates a variety of modalities. Ideas for visual presentation as well as student products include cartoons, storyboards, posters, graphs, graphs, charts, videos, games, and demonstrations. For oral presentation and student products, use audiotapes, videos, lecture, song, discussion, debate, and assistive technology incorporating text to speech. When looking at written means of presentation and student products, ideas include case studies, stories, journals, exit slips, graphic organizers, and assigned readings. Following a discussion of the importance of considering Visual, Oral, and Written aspects of classroom instruction, processing might include these prompts

- Think of a concept that you teach which would be a good candidate for a VOW representation

- Write down how you would deliver the content

- Share with a partner, asking your partner to provide points of clarification, concerns, strengths, and suggestions.

At the conclusion of a professional development, an activity designed to assist faculty in incorporating UDL principles into their instruction is the development of an action plan for next steps (see Appendix B). This helps ensure that faculty will continue to process and incorporate UDL into their classrooms. Guiding questions for development of an effective action plan include

- How will I represent the what, how, and why of UDL in my classroom?

- What concepts or topics will I use to create multiple delivery modalities?

- How will I facilitate engagement of these concepts and topics?

- How will I support how students demonstrate their learning of these concepts/topics through various modalities?

- How will I hold myself accountable for effective implementation and assessment of these strategies? 


\section{University Classroom Recommendations}

When preparing to teach in the university classroom, most instructors typically spend their time preparing the content of the syllabus, outlining the semester, and seeking ways to ensure that all the content pieces are included. Gone are the days when an instructor can simply stand at the front of the lecture hall and dispense knowledge. As a result of an inclusive philosophy and laws, such as the Americans with Disabilities Act (1990), colleges and universities have candidates with sensory issues, such as blindness or deafness, they have candidates with learning disabilities such as dyslexia, and they have candidates with language differences, to name a few. What about them? How does the instructor make sure they access critical content? For starters, faculty can make sure that they incorporate multiple modalities-vision, hearing, and touch. When instructors prepare their lessons, they can ask themselves if their presentation will be accessible to everyone, or if this is just the way faculty are used to delivering content.

Taking each of the three principles and examining them more closely, the university professor can find multiple ways to embed strategies into his/her instruction. With a UDL focus, faculty must consider the many ways students access information; this is the "what" of learning, and targets the first principle, providing multiple means of representation. Instructors can adapt their format by amplifying sound or providing captions, enlarging text, changing the font, or even using color to emphasize major points. Instructors can provide hands-on experiences using models or manipulatives.

Other ways to provide multiple means of representation involve a careful examination of the various types of language, expressions and symbols that are used. For some students with disabilities, the use of idioms may be confusing. If this happens, explaining the meaning of the idiom can enhance understanding. Some students may need to have key words or vocabulary clarified, defined, or even illustrated. New language can be linked to candidates' previous knowledge so that connections can be made. Some candidates may struggle with symbolic language, and pictures or images may assist in comprehension. Tables, models, videos, animation, and even comic strips can all be utilized to provide multiple means of representation. Although there are countless other ideas, these are just a few of the myriad of ways that multiple means of representation can be approached.

The second principle, as indicated earlier, providing multiple means of action and expression, refers to the "how" of learning. How do faculty ensure that their candidates convey what they are learning? Candidates must be able to express themselves and represent what they know in a variety of ways. For instance, some may need to verbally express their understanding, while others may need to express themselves more accurately in writing. Some candidates are challenged by movement impairments, while others may struggle with organization or language. Universities have candidates with physical challenges, and for them, using alternatives to pen and pencil or even a mouse may be indicated. Thankfully, technological advances have provided such tools as adapted keyboards, joysticks and voice activated programs or switches. In addition to the tools, support is also needed.

Other means of expression include interactive web tools or social media. There are a variety of software programs such as those designed to check spelling or grammar, predict words, or convert text to speech that might be considerations. Support in the form of gradually released scaffolding, working toward increased fluency, or providing customized feedback can also be considered as providing multiple means of action and expression. The standard textbook may not be conducive to learning for the candidate with physical disabilities, so providing alternative means for response is imperative. Some additional ideas for focusing on the "how" of learning include use of multiple media such as film, music, dance, or other forms of movement. Finally, the attentive professor assists the candidate in identifying models, guidelines, checklists, and schedules to promote learning. The possibilities are seemingly endless.

The last principle targets the myriad ways that professors assist in increasing the likelihood that candidates are able to be engaged or motivated to learn, the "why" of learning. The attentive professor understands that candidates are different in what engages their interest and attracts their attention. Candidates need to be offered choices in how objectives can be reached as well as choices in identifying and setting personal and academic goals. Relating instruction to candidates' culture, personal lives, and other individual characteristics is also essential. Careful attention to the provision of a safe, supportive environment is a key element. One idea for ensuring that the classroom is supportive is to provide cues such as calendars, schedules, or visible timers when seeking to meet candidates' needs.

While attending to multiple means of engagement, the attentive professor realizes that some candidates differ in their level of motivation and/or their self-regulatory skills. Some candidates may need to have long term goals broken into short term steps, or they may need to be frequently reminded about the ultimate goal. Others may need careful scaffolding to help them visualize their desired outcome. At times, the professor may need to reinforce effort and improvement regularly. The creation of cooperative and supportive groups or other peer support opportunities may meet the needs of some candidates. Another way to provide support is the use of coaches or mentors to assist 
candidates in reaching their goals. An ultimate outcome, hopefully, is to assist the candidate and their ability to move along the continuum towards achievement of what is most important to him or her.

\section{Final Thoughts}

When viewed collectively, UDL means that information is presented in a flexible manner, taking into account how candidates express themselves, and in what ways candidates are engaged. In short, all students have access to the curriculum in ways meaningful to each individual. Some have said that the purpose of education is to help an individual grow beyond what he believes he can be. Others might say that it is to create a love for lifetime learning. Whether education sparks an unquenchable thirst or provides a means to achieve a personal goal, ensuring access by all learners becomes the responsibility of everyone who would calls themselves teachers. By definition, teaching involves causing or helping another to learn. When contemplating diversity of those who wish to learn, it is imperative that those who choose to teach, persist in making their instruction accessible to all who wish to engage in the learning process. Universal design provides a critical framework for making that happen.

\section{References}

Capp, M. J. (2017). The effectiveness of universal design for learning: a meta-analysis of literature between 2013 and 2016. International Journal of Inclusive Education, 21(8), 791-807. https://doi.org/10.1080/13603116.2017.1325074

Fuentes, S.S., Castro, L., Casas, J.A., Vallejo, V., \& Zuniga, D. (2016). Teacher perceptions based on universal design for learning. Communication Disorders, Deaf Studies, \& Hearing Aides, 4(1), n.p. https://doi.org/10.4172/2375-4427.100155

Grogan, D., \& Ruzic, R. (2000). Walking the walk: universal design on the Web. Journal of Special Education Technology, 15(3), $\quad$ Retrieved from https://ucark.idm.oclc.org/login?url=https://search.ebscohost.com/login.aspx?direct=true $\& d b=e u e \& A N=507708$ $324 \&$ site $=$ ehost-live $\&$ scope $=$ site

Katz, J. (2015). Implementing the three block model of universal design for learning: effects on teachers' self-efficacy, stress, and job satisfaction in inclusive classrooms K-12. International Journal of Inclusive Education, 19(1), 1-20. https://doi.org/10.1080/13603116.2014.881569

Knowles, M. S. (1989). The making of an adult educator. San Francisco, CA: Jossey-Bass, Inc.

Lohmann, M. J., Boothe, K. A., Hathcote, A. R., \& Turpin, A. (2018). Engaging graduate students in the online learning environment: a universal design for learning (UDL) approach to teacher preparation. Networks: An Online Journal for Teacher Research, 20(2), 1-23. https://doi.org/10.4148/2740-6353.1264

Mangiatordi, A., \& Serenelli, F. (2013). Universal design for learning: A meta-analytic review of 80 abstracts from peer reviewed journals. Research on Education and Media, 5(1), 109-118.

McGuire, J. M., \& Scott, S. S. (2009). Universal Design for Instruction: Extending the Universal Design Paradigm to College Instruction. Journal of Postsecondary Education and Disability, 19(2). 


\section{Appendix A. UDL Action Plan}

\begin{tabular}{l}
\multicolumn{1}{c}{ Guiding Questions } \\
\hline $\begin{array}{l}\text { How will I represent the what, how, and why } \\
\text { of UDL in my classroom? }\end{array}$ \\
\hline $\begin{array}{l}\text { What concepts or topics will I use to create } \\
\text { multiple delivery modalities? }\end{array}$ \\
\hline $\begin{array}{l}\text { How will I facilitate engagement of these } \\
\text { concepts and topics? }\end{array}$ \\
$\begin{array}{l}\text { How will I support how students demonstrate } \\
\text { their learning of these concepts/topics through } \\
\text { various modalities? }\end{array}$ \\
\hline $\begin{array}{l}\text { How will I hold myself accountable for } \\
\text { effective implementation and assessment of } \\
\text { these strategies? }\end{array}$ \\
\hline
\end{tabular}

